\title{
Interactive comment on "Characterizing the evolution of physical properties and mixing state of black carbon particles: from near a major highway to the broader urban plume in Los Angeles" by Trevor S. Krasowsky et al.
}

\section{G. Ban-Weiss}

banweiss@usc.edu

Received and published: 13 November 2017

Dear reviewer, Thank you for your comment. We will upload new versions of Figures 3, 5, and 11 with larger axis labels and less grid lines (in Figure 11). The first author is currently on travel so it will take us a few days. In the meantime, I upload larger versions of these three figures in case it helps facilitate the review process. Thanks! 
ACPD

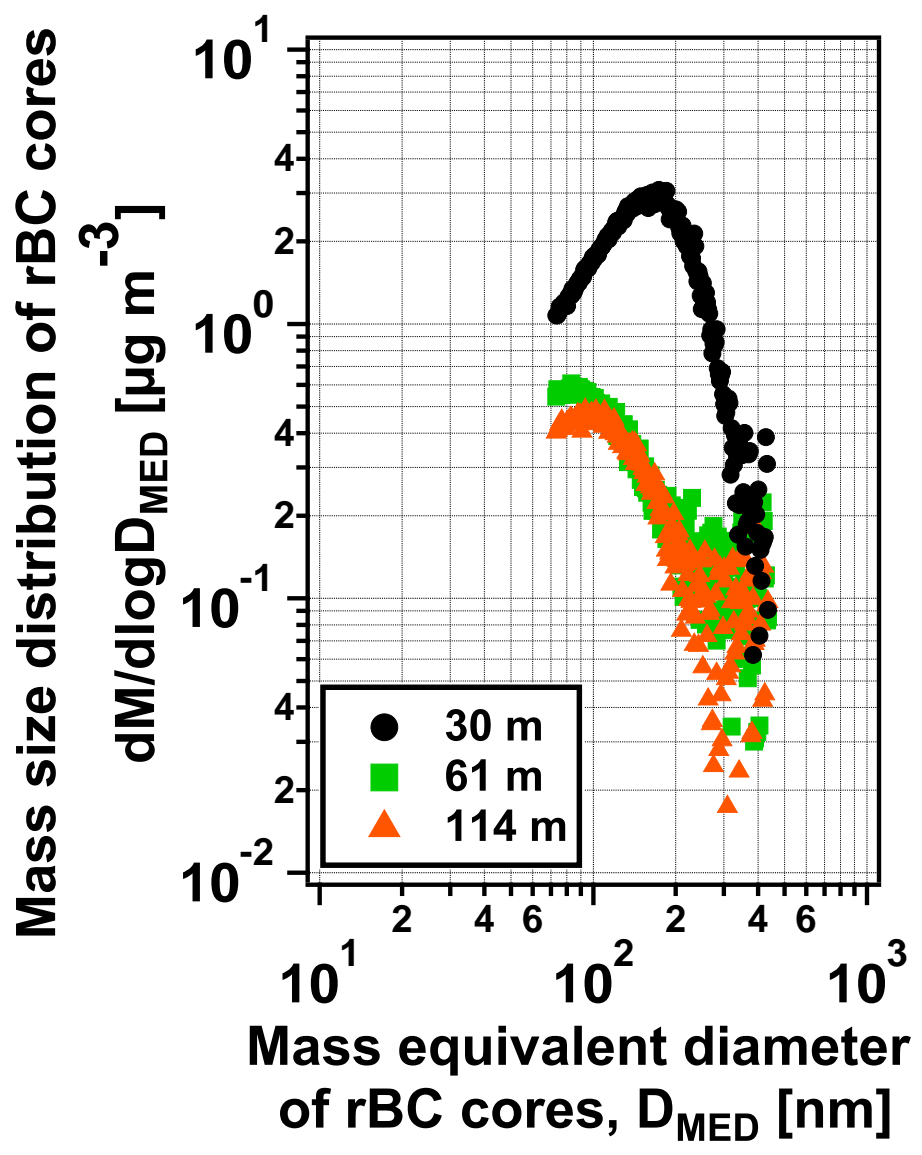

Interactive

comment

Printer-friendly version

Discussion paper

Fig. 1. Figure 3a

(c) 
ACPD

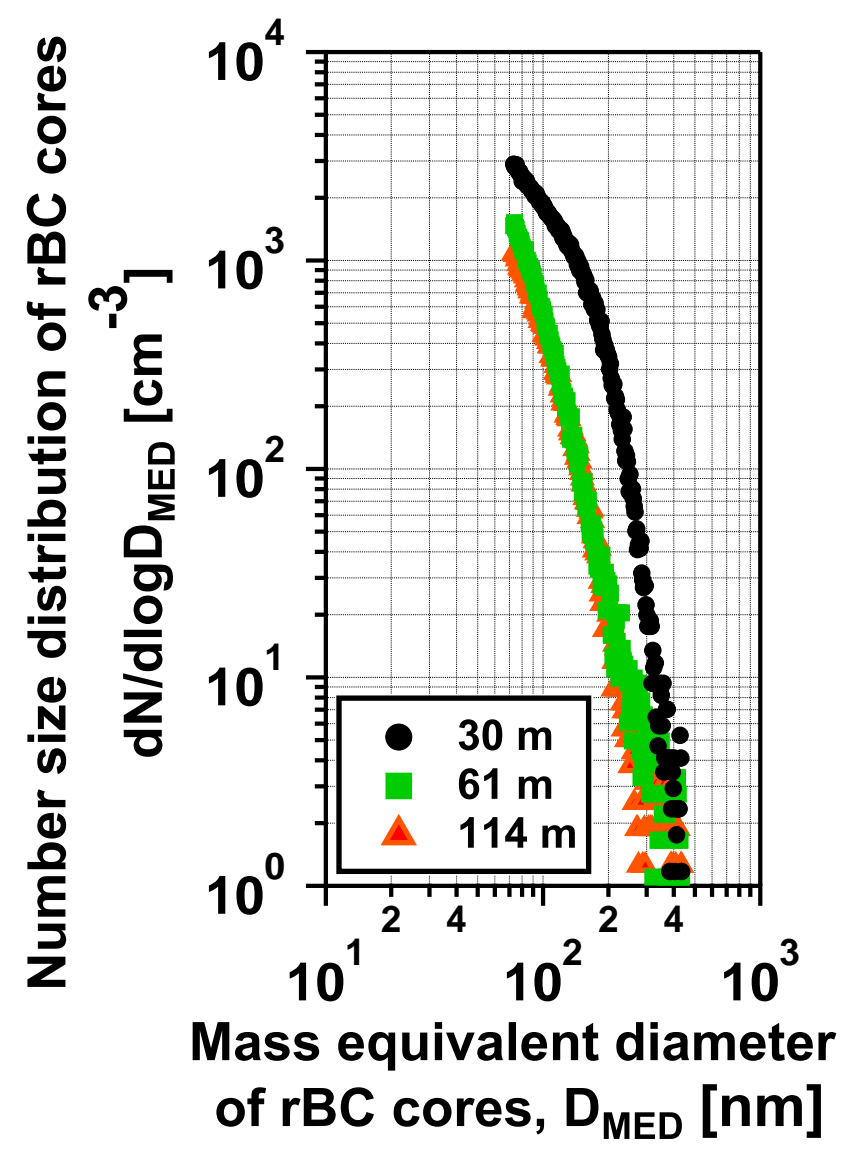

Interactive

comment

Printer-friendly version

Discussion paper

Fig. 2. Figure $3 b$ 


\section{Interactive \\ comment}

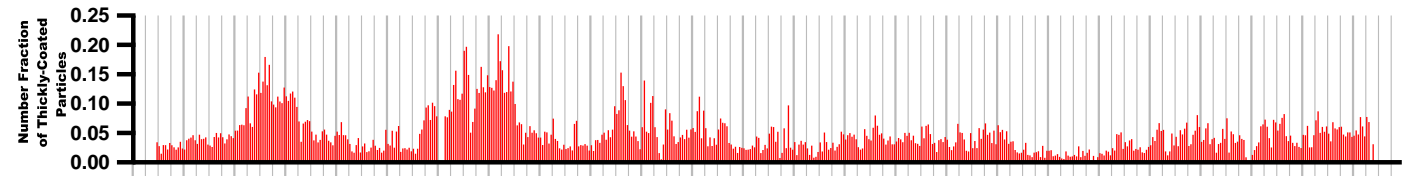

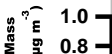

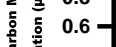

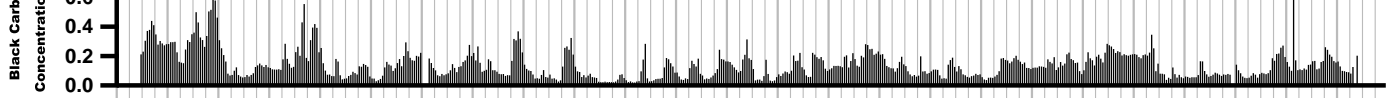
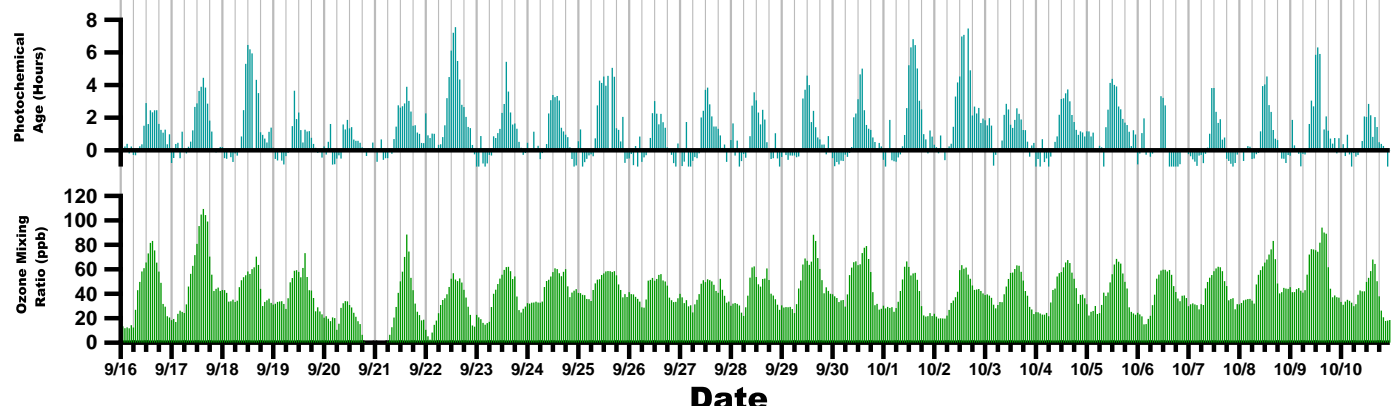

Date

Fig. 3. Figure 5 

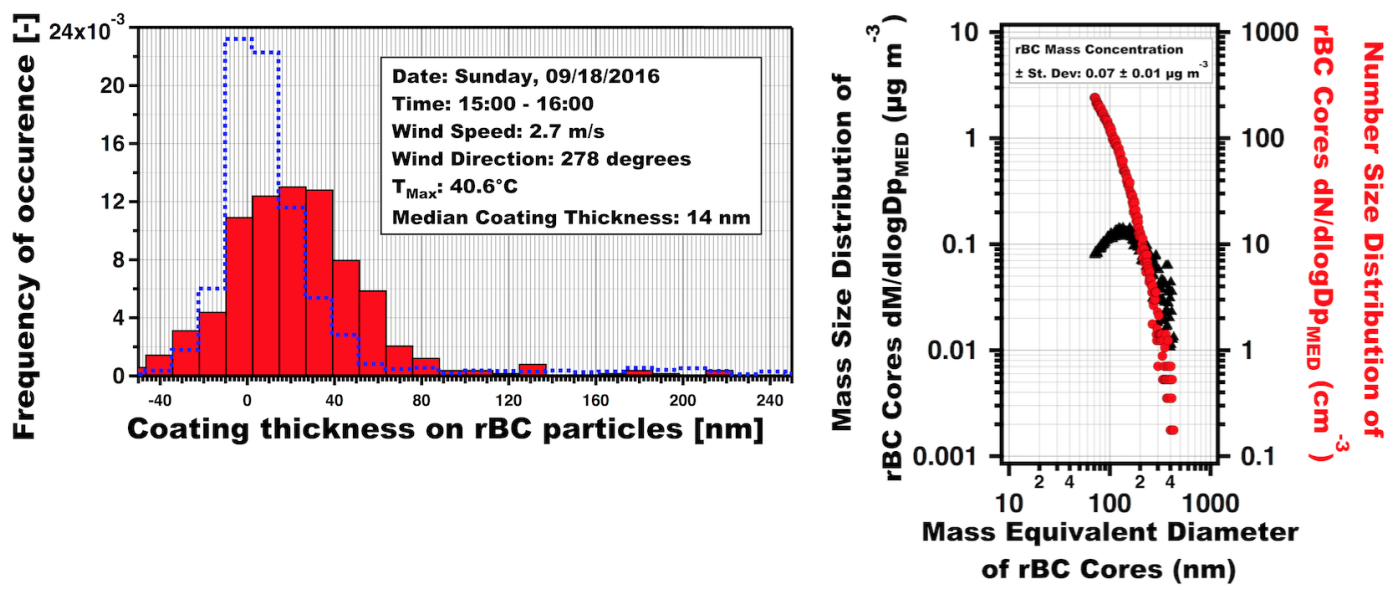

Fig. 4. Figure 11 first row 

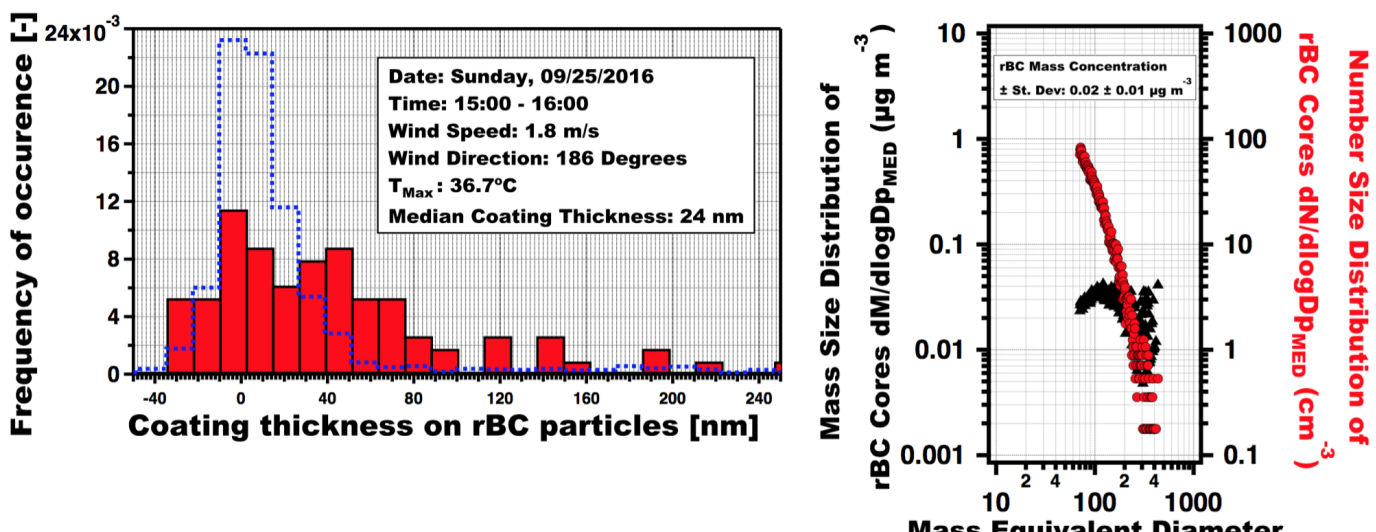

Mass Equivalent Diameter

of rBC Cores (nm)

Fig. 5. Figure 11 second row 

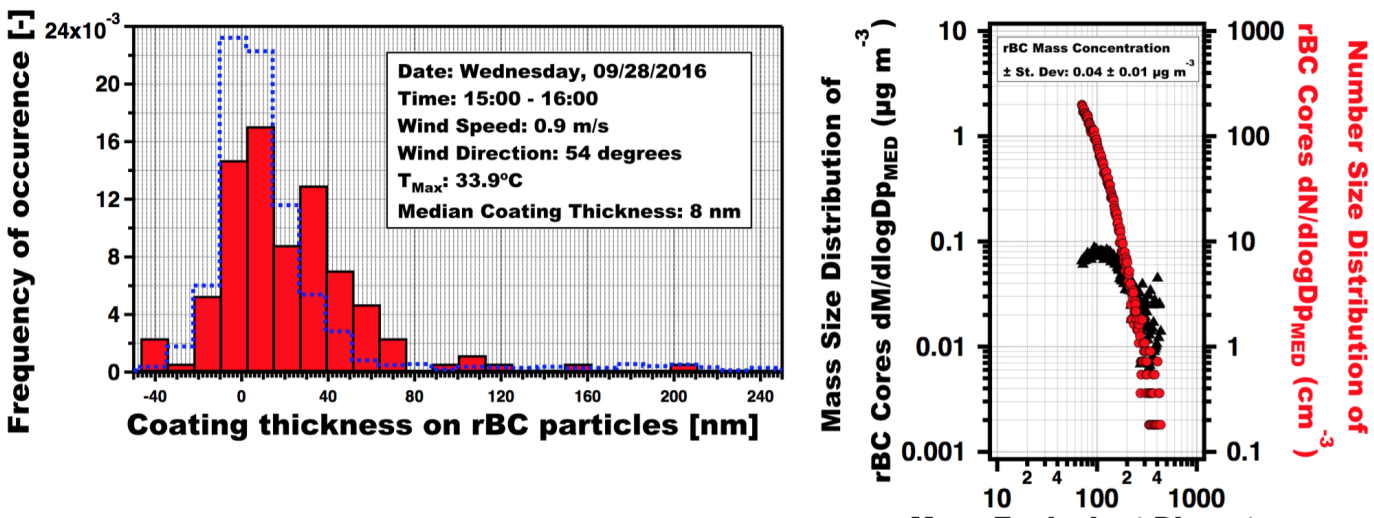

Mass Equivalent Diameter of rBC Cores (nm)

Fig. 6. Figure 11 third row 

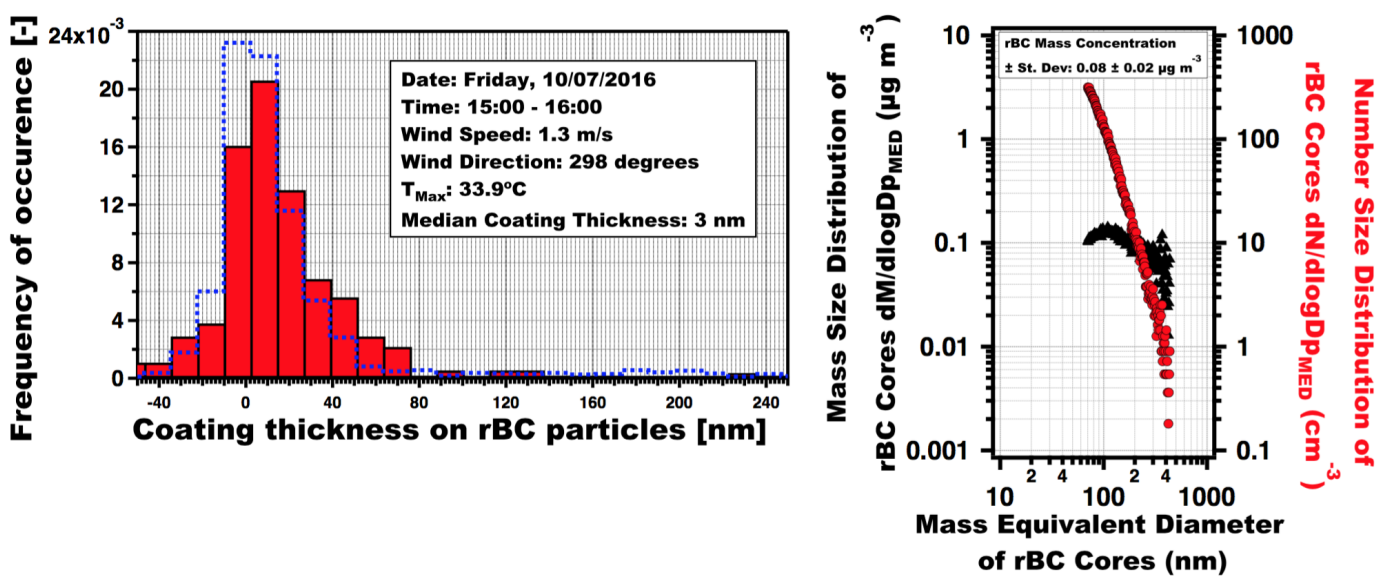

Fig. 7. Figure 11 fourth row 